
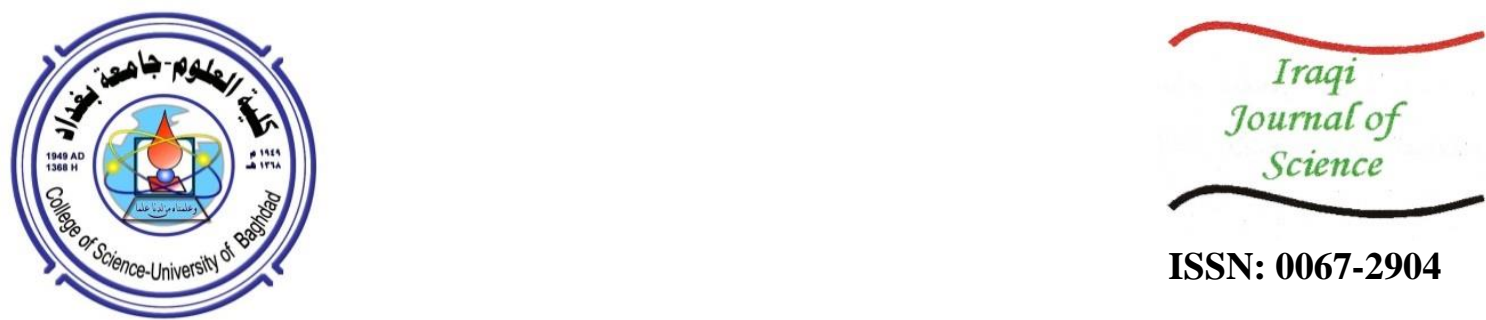

ISSN: 0067-2904

\title{
Measurement of Pollution Level with Particulate Matter in Babylon Concrete Plant and Evaluation of Oxidative Stress and Hematological Profile of Plant Workers
}

\author{
Shaimaa H. Al-Dulaimi* , Adel M. Rabee \\ Department of Biology, College of Science, University of Baghdad, Baghdad, Iraq
}

Received: 17/12/2020

Accepted: 19/3/2021

\begin{abstract}
The impact of exposure to different sizes of particulate matter $\left(\mathrm{PM}_{1}, \mathrm{PM}_{2.5}, \mathrm{PM}_{7}\right.$, and $\mathrm{PM}_{10}$ ) was evaluated in Babylon concrete plant workers who had been exposed to concrete dust for at least 10 years. The effects of these particles on the hematological parameters, malondialdehyde (MDA) levels, and antioxidant enzymes (catalase and glutathione peroxidase ) were examined. The results exhibited that the levels of PM2.5 and PM10 were higher than the acceptable limits approved by the National Ambient Air Quality Standards (NAAQS). The blood parameters, namely white blood cells (WBC), red blood cell (RBC) and platelets counts, demonstrated non-significant differences between workers exposed to the PM as compared to the control group. However, differentiated white blood cells count revealed a significant increase of polymorphonuclear leukocytes (PMN) in exposed workers in comparison with the control group. However, both MDA and glutathione peroxidase showed a highly significant increase in the workers ass compared to the control group. Thus, we may conclude that the concrete plant workers are exposed to a higher risk of oxidative stress that could lead to alterations in hematological parameters, enzymatic activities, and MDA level.
\end{abstract}

Keywords: concrete dust, free radical production, Lipid peroxidation, oxidative damage.

\section{قياس مستوى التلوث بالدقائق العالقة في معمل الخرسانة في بابل و تقييم الجها التأكسدي وبعض مؤشرات الام لعمال المعمل}




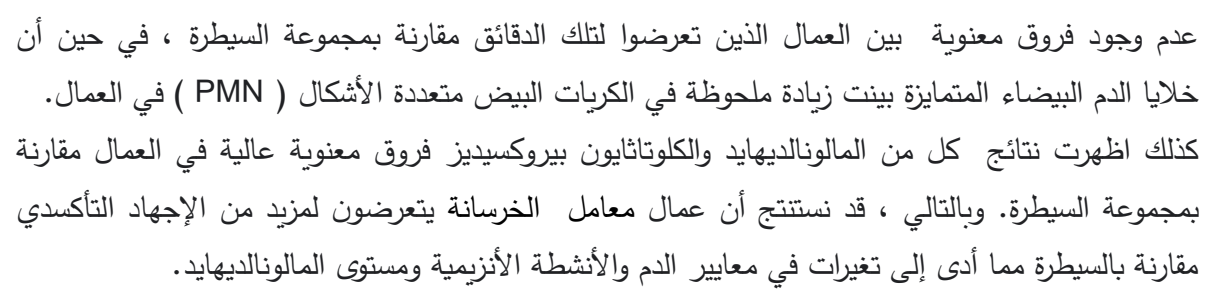

\section{Introduction}

Concrete production is the greatest source of particulate matter (PM) discharge, accounting for $20-30 \%$ which is $40 \%$ of the absolute industrial emission [1,2]. Within a concrete production line, significant measures of PM as residue are performed at each phase of the industrialization process; from quarrying of the crude substance to the bundling [3]. Concrete dust is an especially alkaline and irritant dust, which may cause more serious damages to the respiratory tract in comparison with other ineffectively solvent dusts [4]. The streamlined measurement of concrete particles range from 0.05 to $10 \mu \mathrm{m}$. This range is inside the range of particles that may breathe and make the tracheobronchial respiratory zone as the essential objective of concrete sedimentation [5]. Numerous articles concerning hurtful impacts of concrete dust (silicates) has been seen to cause respiratory infections and weakened lung work and furthermore increases free radical creation. The mechanisms for these impacts are not completely seen, yet there might be a connection with asbestos and particularly with reactive oxygen species (ROS), on the grounds that an expansion in the degree of ROS and the level of antioxidant enzyme has a significant role in endothelial cell work [6]. However, constant exposure to concrete dust can prompt damaging impacts on the skin, eye, respiratory tract, and blood. Long-time exposure to concrete residues causes irritation to the exposed mucous membranes and leads to persistent respiratory diseases, including pneumoconiosis and cellular breakdown in the lungs [7,8]. Various studies have shown changes in biochemical and hematological parameters of blood in response to short and long-term exposure to air suspended solids, whereby changes in blood parameters have been significantly correlated with the concentration of PM2.5 particles [9]. Lipid peroxidation, oxidative damage, and immunologic processes have been reported as pathologic components of concrete residue-prompted toxicities [10]. The objective of this study, which was conducted in Babylon cement factory, Babylon, Iraq, during February 2019 to determine pollution levels with suspended particles and assess the their impacts on hematological parameters, lipid peroxidation, and levels of antioxidant enzymes in workers who had been exposed to concrete dust throughout the previous 10 years. These parameters are markers to investigate the degree of free radical damage in the essential organs.

\section{Methods and materials}

\subsection{Equipment}

Major equipment used in the present study included a portable Sniffer device equipped by the Rotheroe \& Mitchll Ltd. company (U.S.A), Met One instrument equipped by Met One Instruments, Inc. U.S. , Twin-X X-Ray Florescence -XRF equipped by Oxford instruments analytical, UK.

\subsection{Study groups}

In the current investigation, samples were gathered from 50 volunteer workers (aged $35 \pm 5$ years) in Babylon concrete plant, who had been exposed to concrete dust for 10 years at least. For all volunteers, permissions were taken from the plant administration and the workers were informed about the aim of the investigation. Forty healthy volunteers with the same age range were selected as unexposed (control) group.

\subsection{PM measurements and component analysis}

Size of PM in air samples taken from Babylon factory was measured by using a portable Met One instrument. Also, the elemental composition of these samples was analyzed by using a 
Snifer device and Whatman filter paper sized $2.5 \mathrm{~mm}$. The filter paper was then examined with an X-Ray Florescence -XRF (Twin-x, Oxford instruments) ().

\subsection{Hematological and biochemical analyses}

$5 \mathrm{ml}$ of blood was collected from each subject, which was then divided into two parts. The first part $(4 \mathrm{ml})$ was placed in a tube, from which the serum was separated by centrifugation. The collected serum was transferred to an Eppendorf tube and kept at $-20 C^{\mathbf{o}}$ until assayed. The second part $(1 \mathrm{ml})$ was transferred to an EDTA tube for complete blood count assay. Malondialdehyde level was determined using Buege and Aust method [11]. MDA results from the breakdown of polyunsaturated fatty acids and used as a suitable index of peroxidation reaction. The thiobarbituric acid method was utilized to assess the level of MDA, which reacts with thiobarbituric acid to give pink colored solution that is read at $\lambda$ max $535 \mathrm{~nm}$ [12]. Catalase activity assay kit (Colorimetric, ab83464) was used to estimate catalase activity in serum. In this test, the catalase present in the sample interacts with hydrogen peroxide $\left(\mathrm{H}_{2} \mathrm{O}_{2}\right)$ to produce water and oxygen. The unconverted $\mathrm{H}_{2} \mathrm{O}_{2}$ interacts with the probe to create a product that can be estimated colorimetrically at an optical density (OD) of $570 \mathrm{~nm}$. Subsequently, the catalase activity in the sample is reversely proportional to the signal gained [13]. Glutathione peroxidase (GPx) activity was measured via the ELIZA technique by using a commercially available kit (Elabscience, USA) [14]. The micro ELISA plate in this kit is pre-covered with antibodies specific to Human GPX1. Samples were added to the micro ELISA plate wells to react with the antibodies. At that point, biotinylated recognition antibodies specific for Human GPX1 and Avidin-Horseradish Peroxidase (HRP) complex were added progressively to each micro-plate well and incubated. Free components were washed away. The substrate was then added to each well. Only those wells that contained Human GPX1, biotinylated recognition antibodies, and Avidin-HRP complex appeared in blue color. The enzyme-substrate response was ended by the addition of the stop solution and the color turned into yellow. The OD was estimated spectrophotometrically at $450 \mathrm{~nm} \pm 2 \mathrm{~nm}$. The OD value is directly proportional to the level of GPX1. The amount of human GPX1 in the samples by was measured by contrasting the OD of the samples with the standard curve.

2.5 Statistical analysis

The Statistical Analysis System-2012[15] program was utilized to analyze the impacts of the different factors used in this investigation. T-test was utilized to compare the mean values and test the significance of differences among them.

\section{Results and discussion}

\subsection{Air pollution data}

Figure 1 shows the mean values of particulate matter with different sizes $\left(\mathrm{PM}_{1}, \mathrm{PM}_{2.5}, \mathrm{PM}_{7}\right.$, $\mathrm{PM}_{10}$ ) and total suspended particle (TSP) emitted from the studied cement plant. These levels were measured to create data on the current amounts of PM emissions from non-controlled plant activities. The results showed that the levels of both $\mathrm{PM}_{2.5}$ and $\mathrm{PM}_{10}(35$ and 150 $\mu \mathrm{g} / \mathrm{m}^{3}$, respectively) were higher than the standard limits of NAAQS [16]. The high $\mathrm{PM}_{2.5}$ and $\mathrm{PM}_{10}$ levels in the cement plant might have led to the accumulation of concrete dust substances in the higher and lower respiratory airways of the tracheobronchial area of the lungs. These substances were possibly the main reason for the symptoms of shortness of breath, chest pain, malaise, coughing, and sneezing [11], which were reported in the replies to the questionnaire provided by the Babylon concrete plant workers. 


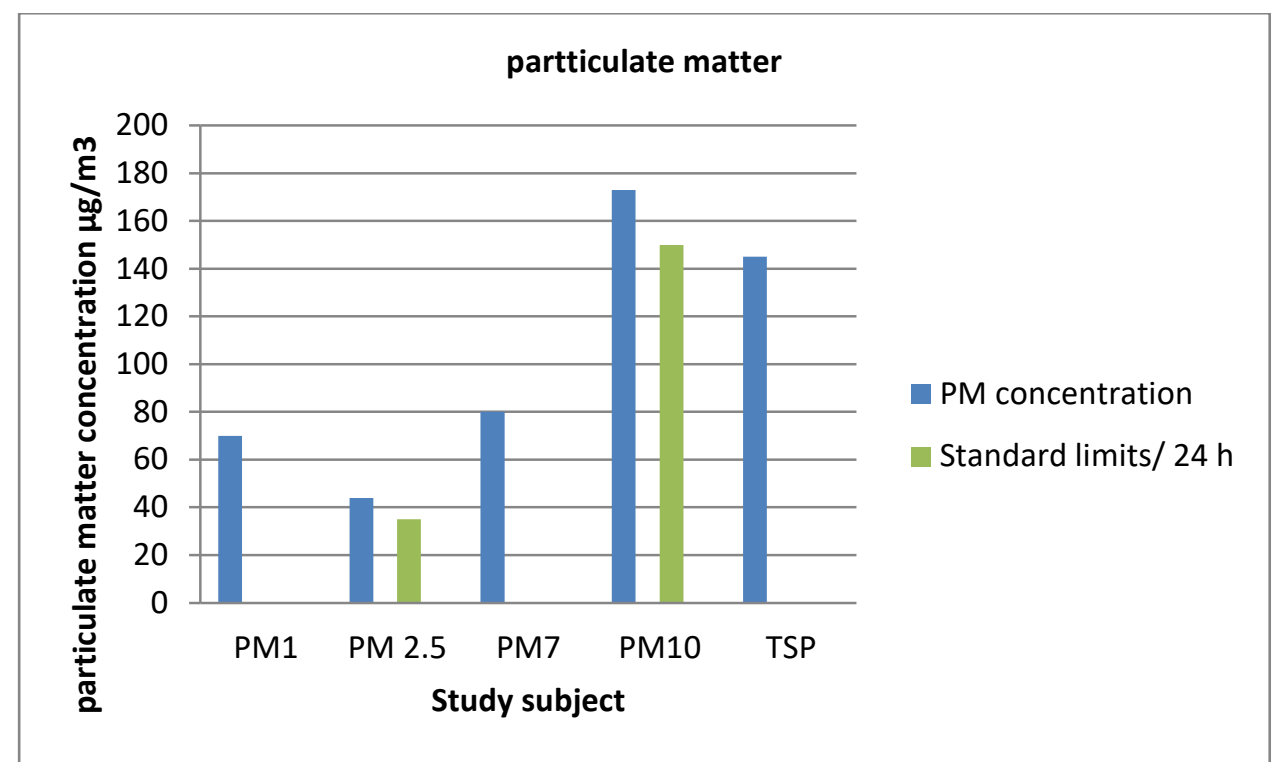

Figure 1- Particulate matter (PM) and total suspended particle (TSP) levels in air samples collected from Babylon concrete plant.

Data air content of elements emission from concrete plant as element oxides as shown in Figure 2. Harmful impacts of exposure to concrete dust constituents on organ framework in people have been depicted. Atoms of essential significance in concrete dust as far as substance and potential health impacts fundamentally incorporate (60-67\%) calcium oxide, (17-25) silicon oxide, and (3-5\%) aluminum oxide, with some measure of iron oxide, chromium, potassium, sodium, sulfur, and magnesium oxide. Occupational exposures to aluminum, iron , calcium, and silicon have been related with diminished lung work markers in exposed laborers [11].The concrete dust or constituents of concrete causes pathogenesis of different lung illnesses including persistent bronchitis, asthma, pneumonia, cancer of lung and tuberculosis [17].

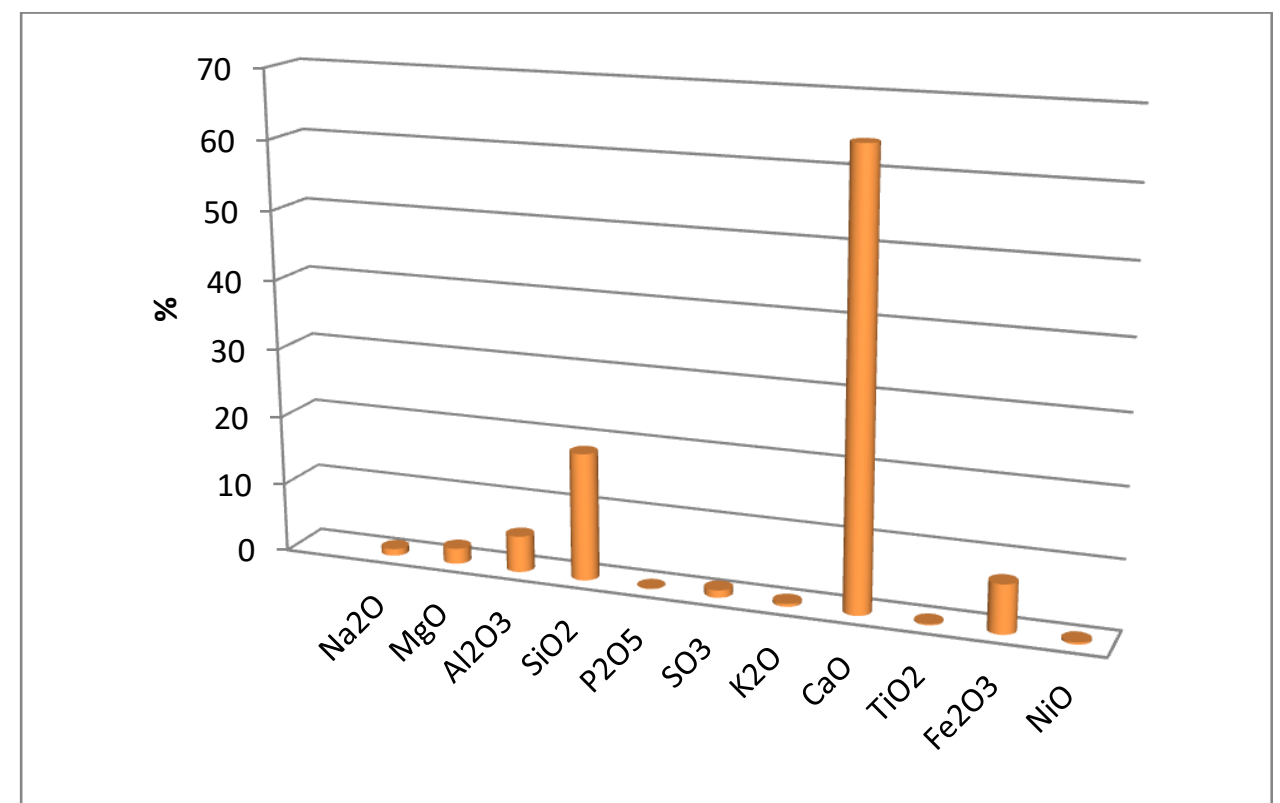

Figure 2-Proportions of oxides of different elements found in the air samples collected from Babylon cement plant. 


\subsection{Hematological parameters}

Air contamination is the origin of numerous particles that may go the human circulation system within the nose, mouth, derm, and the digestive canal. Most air poisons arrive at the circulation system rapidly with no prior bio transformation and have been appeared to create hurtful consequences for the blood, bone marrow, lymph nodes and spleen [18]. Occupational exposure to concrete dust has a significant impact on hematological parameters [19]. A previous review of literature proposed that persistent exposure to harmful ingredients of concrete dust (hexavalent chromium, crystalline silica, calcium oxide, and aluminum) stimulates inflammation and recruitment of neutrophils, macrophages, and lymphocytes in the lungs. Minute substances like concrete dust can also pass into the circulation [20]. Differences in hematological profiles between cement workers and control subjects are given in Table 1. The results indicated insignificant differences between the two groups in the counts of red blood cells, white blood cells, and platelets. This finding does not agree with previous reports $[21,22,23]$. Regarding the differential count of white blood cells, the results showed that the number of the PMNs was significantly increased in the blood of workers as compared to the control group $(\mathrm{P} \leq 0.05)$, whereas there was no significant difference in the total lymphocyte and monocyte counts between the two groups. Polymorphonuclear leukocytes are assumed to have essential rules in the immune responses, being considered as the first line of defense against bacterial and parasitic diseases. Their role in the inflammatory mechanisms was once thought to be confined to phagocytosis and the arrival of enzymes and other cytotoxic factors. Yet, it is presently realized that these cells can deliver different mediators that have heavy impacts on the airways of asthmatic people [24]. Increase PMN in differential counts can improve the theory of that the fundamental reaction of breathing contaminated air with significant levels of PM2.5 and PM10 improved increase the circulating PMN cells. This elevation might be attributed to the movement of WBCs and their precursors from the bone marrow due to the sedimentation of particles in the lung. These cells are generally found in the marrow and represent 2 to $6 \%$ of the typical circulating WBCs, and any elevation in their number demonstrates that the marrow has an increased activity in the production of PMN cells [25]. Association between an acute air pollution episode due to the Southeast Asian Smoke-haze in 1997 and the development of elevated band cells expressed as a percentage of total PMN in healthy military recruits with maximal coherences with PM10 [26]. We presume that the absence of an elevate in circulating monocytes after PM introduction is because of particular sequestration and induction of monocytes into the lung remove and these finding is coincide with previous studies [27].

Table 1-Blood parameters workers exposed to concrete dust and of healthy control.

\begin{tabular}{|c|c|c|}
\hline Parameter & control $/ \mathrm{N}=40$ & Workers $/ \mathrm{N}=50$ \\
\hline RBC count $\left(\times 10^{12} / \mathrm{L}\right)$ & $5.27 \pm 0.14$ & $5.50 \pm 0.21$ \\
\hline WBC $\operatorname{count}\left(\times 10^{9} / \mathrm{L}\right)$ & $7.35 \pm 0.41$ & $8.73 \pm 0.69$ \\
\hline PLT $\operatorname{count}\left(\mathrm{x} 10^{9} / \mathrm{L}\right)$ & $229.60 \pm 24.66$ & $268.60 \pm 9.59$ \\
\hline PMN \% & $52.86 \pm 2.74$ & $61.15 \pm 2.44 *$ \\
\hline Lympho \% & $36.98 \pm 2.85$ & $32.83 \pm 2.37$ \\
\hline Mono\% & $6.30 \pm 0.46$ & $6.02 \pm 0.46$ \\
\hline
\end{tabular}

Data are expressed as Mean \pm S.E; $(\mathrm{N})$ the number of volunteers. *Different Significantly at $\mathrm{P}<0.05$. RBC: red blood cell; WBC: white blood cell; PLT: platelets; PMN: polymorphonuclear leukocytes; Lympho: lymphocytes; Mono: monocytes.

\subsection{Biochemical parameters}

Oxidative stress is believed to occur when there is an imbalance in the biological oxidant to antioxidant ratio [28]. One hypothesis to explain the observed adverse health effects in the present study is that particle matter can induce oxidative stress mediated by a particle-induced inflammation, causing macrophages to release reactive oxygen species, by transition metals 
on the particle surface capable of generating ROS through Fenton reaction or by quinones in the particles that produce ROS through redox cycling [29,30]. Lipids are examples of molecules that can be altered by increased ROS levels in vivo. Some of these alterations are known to have direct impacts on the functions of target molecules; for example, the inhibition of enzymatic activities. However, other modifications just reflect a local degree of oxidative stress ]31]. The effects of exposure to concrete dust on MDA level and antioxidant enzyme activities are shown in Table 2 . Exposure to concrete dust caused a highly significant increase $(\mathrm{P} \leq 0.01)$ in the serum levels of MDA and GPXin the workers compared to the control, while serum level of catalase (CAT) activity exhibited an insignificant increase in the workers. We also noticed that concrete workers had a generally greater extent of increase in MDA and GPx levels because of the increased air contamination. These results propose that concrete dust can stimulate the release of ROS and activate lipid peroxidation. In addition, serum level of GPX was increased due to continuous exposure to concrete dust; it may be associated to long time exposure. Workers also showed higher levels of of oxidant and antioxidant factors, which may be caused by the continuous production of free radicals and lipid peroxidation with continuous exposure [32]. This finding is in disagreement with other researchers who found that the increases in MDA in exhaled breath condensate (EBC) is directly proportional with increases in particulate pollutants [33]. Malondialdehyde was significantly associated with concentrations of aerodynamic fine particulate matter with diameter less than $2.5 \mu \mathrm{m}$ [34]. Also antioxidant enzymes like GPX and superoxide dismutase (SOD) were reported to have a significant decrease, while CAT showed a marked increase, in workers involved in construction activities [35]. However, other results found that the CAT activity in workers exposed to concrete dust was significantly lower than in the control group [36, 37].

Table 2-Effects of concrete dust on antioxidants enzymes and serum malondialdehyde of concrete plant workers and unexposed control

\begin{tabular}{|c|c|c|}
\hline Parameters & Healthy control $/ \mathrm{N}=40$ & Exposed laborers $/ \mathrm{N}=50$ \\
\hline $\mathrm{MDA}(\mu \mathrm{mol} / \mathrm{L})$ & $1.310 \pm 0.025$ & $1.638 \pm 0.054 *$ \\
\hline $\mathrm{GPX}(\mathrm{pg} / \mathrm{ml})$ & $7901.81 \pm 2589.82$ & $33490.31 \pm 5279.26$ \\
\hline $\mathrm{CAT}(\mathrm{nmol} / \mathrm{ml})$ & $0.00145 \pm 0.0003$ & $0.00177 \pm 0.0546$ \\
\hline
\end{tabular}

Data are Mean \pm S.E; $(\mathrm{N})$ the number of volunteers. ${ }^{*}$ Different Significantly at $P<0.01$. MDA: malondialdehyde ;GPX: Glutathione peroxidase ; CAT: catalase.

\section{Conclusions}

In conclusion, the current information indicated that the exposure to concrete dust is the reason for stimulating free radicals and the marked harmful modifications in some hematological parameters, enzymatic functions, and MDA level, probably causing deleterious effects on human health. Therefore, to protect 1 their health, workers must be provided with occupational safety equipment; for example, they should wear appropriate clothing, gloves, safety goggles, and earplugs, while all work areas should be well ventilated. Moreover, support to these results comes from other investigations which stated that concrete laborers should be supplemented with cancer prevention nutrients; for example, ascorbic acid and $\mu$ tocopherol, which can improve plasma antioxidant enzymes [38].

\section{Acknowledgments}

The authors would like to thank and acknowledge the concrete plant workers and control group who volunteered for this investigation and facilitated its completion. 


\section{References}

[1] F. Sanchez-Soberon, J. Rovira, M. Mari and et al., "Main components and human health risks assessment of PM 10, PM 2.5, and PM 1 in two areas influenced by cement plants," Atmos Environ, vol.120, pp.109-116, 2015.

[2] Sh. Hua, H. Tian, K. Wang and et al., "Atmospheric emission inventory of hazardous air pollutants from China's cement plants: temporal trends, spatial variation characteristics and scenario projections, " Atmos Environ, vol. 128, pp.1-9, 2016.

[3] S. Abdul-Wahab, "Impact of fugitive dust emissions from cement plants on nearby communities," Ecol. Modell, vol. 195, pp. 338-348, 2006.

[4] C. Yang, C. Huang, H. Chiu and et al., "Effects of occupational dust exposure on the respiratory health of portland cement workers, " J Toxicol Environ Health, vol. 49, pp.581-588, 1996.

[5] S. El Jabale, "Effect Of Exposure To Cement Dust On Pulmonary Function Among Cement Plants Workers In The Middle Governorate, " M.Sc. Thesis, Department of Science in Environmental health, Gaza, Palestine, pp. 7 ,2015. (In English ).

[6] N. Nur, Y. Abdülkerim, E. Serpil and et al., "Effects of cement dust exposure on malonyldialdehyde levels and catalaze activities in red blood cells," Asian J. Chem, vol. 20, no. 3, pp. 1815-1820, 2008.

[7] M. Gulumian, P. Born, V. Vallyathan and et al., "Mechanistically identified suitable biomarkers of exposure, effect, and susceptibility for silicosis and coal worker's pneumoconiosis: a comprehensive review," J Toxicol Environ Health, part B 2006, vol. 9, no. 5, pp. 357-95, 2006 .

[8] S. Rampuri, "Study and analysis of occupational \& health diseases in cement industries," Int $J$ Adv Res Dev, vol. 2 no.3, pp.1-7, .2017.

[9] M. Riediker, WE. Cascio, TR. Griggs and et al., "Particulate matter exposure in cars is associated with cardiovascular effects in healthy young men," Am J Respir Crit Care Med, vol.169,no.8, pp. 934-40, 2004.

[10] E. Richard, A. Nsonwu-anyanwu, S. Offor and et al., "Cement dust exposure and perturbations in some elements and lung and liver functions of cement factory workers," $J T$, vol .4,pp. 1-7, 2016.

[11] A. Nur, J. Nusrat and Rafiquzzaman, "Review on in vivo and in vitro methods evaluation of antioxidant activity," SPJ, vol. 21, no.2, pp.143-152, 2013.

[12] J. Buege, and S. Aust, "Microsomal lipid peroxidation," Methods- enzymol, vol. 52, pp. 302- 310, 1978.

[13] https://www.abcam.com/catalase-activity-assay-kit

[14] www.elabscience.com

[15] (SAS. 2012) Statistical Analysis System, User's Guide. Statistical. Version 9.1 ${ }^{\text {th }}$ ed. SAS. Inst. Inc. Cary. N.C. USA.

[16] (NAAQS)National Ambient Air Quality Standards.2012

[17] A. Rahmani, A. Almatroudi, Y. Ali and et al., "Effect of exposure to cement dust among the workers: an evaluation of health related complications," Maced. J Med Sci, vol. 6, no. 6, pp.1159$1162,2018$.

[18] M. Nikolić, D. Nikić, and A. Stanković, "Effects of air pollution on red blood cells in children," Polish J of Environ Stud, vol.17,no. 2 ,pp. 267-271, 2008.

[19] A. Farheen, H. Mohammed, Kh, Farisa and et al., "Hematological parameters are acutely effected by cement dust exposure in construction workers," Ann Med Physiol, vol. 1 ,no. 1 ,pp. $31-35$, 2017.

[20] R. Ahmad and Q. Akhter, "Effects of exposure to cement dust on hemoglobin concentration and total count of rbc in cement factory workers," J Bangladesh Soc Physiol, vol. 13, no.2,pp. 68-72, .2018 .

[21] P. Poursafa, K. Roya, A. Amin and et al., "Association of air pollution and hematologic parameters in children and adolescents," J Pediatr, vol. 87, no.4,pp.350-356, 2011.

[22] T. Emmanuel, U. Ibiam, A. Okaka and et al., "Effects of cement dust on the hematological parameters in obajana cement factory workers," ESJ, vol. 27, no.11,pp. $1857-1878,2015$.

[23] A. K. Fauzie and G.V. Venkataramana, "Effects of chronic exposure to particulate air pollution on cardiovascular system: an experimental study using mice models," $J$ of Physics, pp. 1351,2019 . 
[24] J. Monteseirín, "Neutrophils And Asthma," J Investig Allergol Clin Immunol, vol. 19,no. 5,pp. 340-354, 2009.

[25] I. Brüske, H. Regina, M. Martin and et al., " Impact of ambient air pollution on the differential white blood cell count in patients with chronic pulmonary disease," Inhal Toxicol, vol. 22, no.3,pp.1-12, 2010.

[26] WC. Tan, D. Qiu, BL. Liam and et al., " The human bone marrow response to acute air pollution caused by forest fires," Am J Respir Crit Care Med, vol.161,pp.1213-1217, 2000.

[27] F. Mojiminiyi, I. Merenu, M. Ibrahim and et al., " The effect of cement dust exposure on haematological and liver function parameters of cement factory workers in Sokoto, Nigeria," Niger J Physiol Sci, vol. 23 ,no.1-2,pp. 111 -114, 2008.

[28] A. Barzilai and KI. Yamamoto , " DNA damages responses to oxidative stress," DNA Repair,vol. 3,pp.1109-1115, 2004.

[29] X. Li, P. Gilmour, K. Donaldson and et al., " In vivo and in vitro proinflammatory effects of particulate air pollution (PM10)," Environ Health Perspect, vol.105 , no.5,pp.1279-1283, 1997.

[30] J. Han. , K. Takeshita and H. Utsumi, " Noninvasive detection of hydroxyl radical generation in lung by diesel exhaust particles," Free Radic Biol Med,vol. 30,pp.516-525, 2001

[31] I. Marrocco, A . Fabio, and P. Ilaria , "Measurement and clinical significance of biomarkers of oxidative stress in humans," Oxid Med Cell Longev, Article ID 6501046 pp. 1-33, 2017.

[32] R. Miao, Z. Xue-Tao, G. Ping and et al., " Effect of oxidative stress on development of silicosis," World J Respirol, vol.2, no.1,pp. 1-5, 2012.

[33] J. Gong, Z. Tong, K. Howard and et al., " Malondialdehyde In Exhaled Breath Condensate And Urine As A Biomarker Of Air Pollution Induced Oxidative Stress," J Expo Sci Environ Epidemiol, vol. 23, no.3,pp. 322-327, 2013.

[34] W. Lin, Z. Tong, X. Tao and et al., " Association between changes in exposure to air pollution and biomarkers of oxidative stress in children before and during the beijing olympics," Am $J$ Epidemiol, vol. 181,no.8,pp.575-583, 2014.

[35] R S. Sreenivasan, C. Vanitha, G. Ezhamani and et al., " Effect of cement and its particulate matters on lipid peroxidation and antioxidant status in the masons," Int J Pharm Bio Sci, vol. 1, no.2,pp.19-25, 2011.

[36] KH . Al Salhen, " Assessment of oxidative stress, haematological, kidney and liver function parameters of Libyan cement factory workers," Journal of American Science, vol. 10, no.5,pp.5865, 2014.

[37] M. Dianat, R. Esmat , B. Mohammad and et al., "The effects of $\mathrm{pm}_{10}$ on electrocardiogram parameters, blood pressure and oxidative stress in healthy rats: the protective effects of vanillic acid," Environ Sci Pollut Res Int , vol.23,no.19,pp.19551-19560, 2016.

[38] S. Aydin, I. Aral, N. Kilic and et al., "The level of antioxidant enzymes, plasma vitamins c and e in cement plant workers," Clin Chim Acta ,vol. 341,pp.193-198, 2004. 